\title{
NWISWeb: New Site for the Nation's Water Data
}

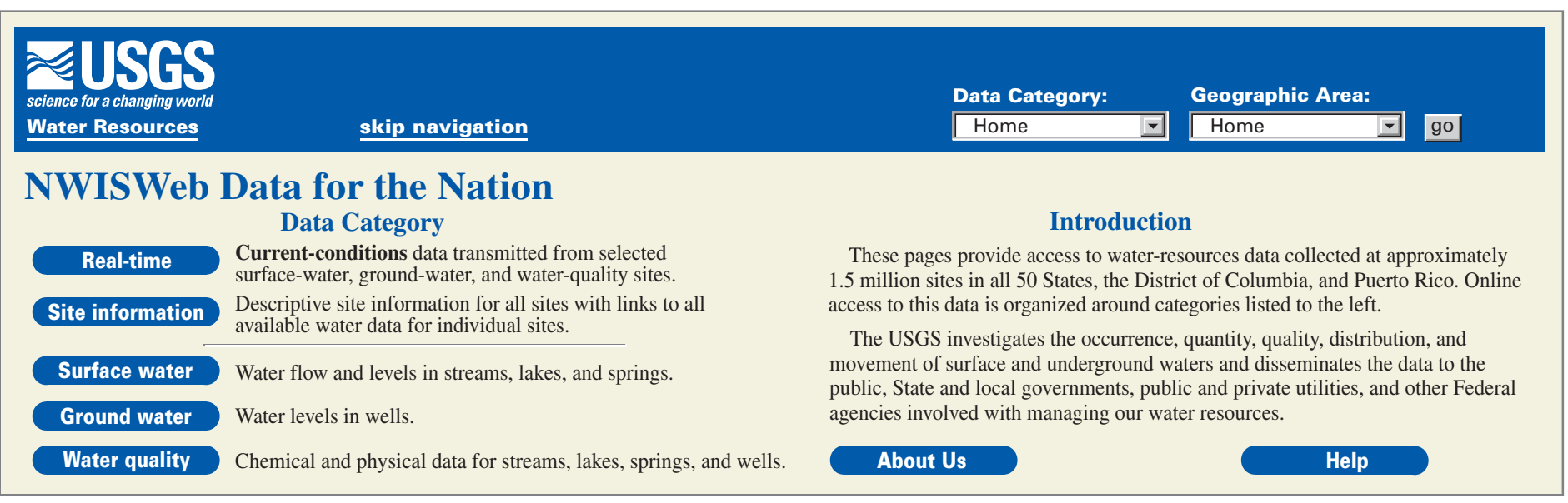

\section{Introduction}

The online National Water Information System (NWISWeb) provides the public with access to more than 100 years of water data collected by the U. S. Geological Survey (USGS). The new Web site (http://waterdata.usgs.gov/nwis/) allows users to access several hundred million pieces of historical and real-time data-all from home or office computers.

"We keep up with the stage and flow on a daily basis."

\section{Data integration}

USGS has been providing real-time and historic streamflow data on the Web since 1994. However, the information was available for each State only through separate Web sites. The NWISWeb system improves that service by aggregating all the data into one national database accessible through one Web site. NWISWeb integrates stream-flow information with many other types of water data, including historic water-quality data from rivers and aquifers, historic ground-

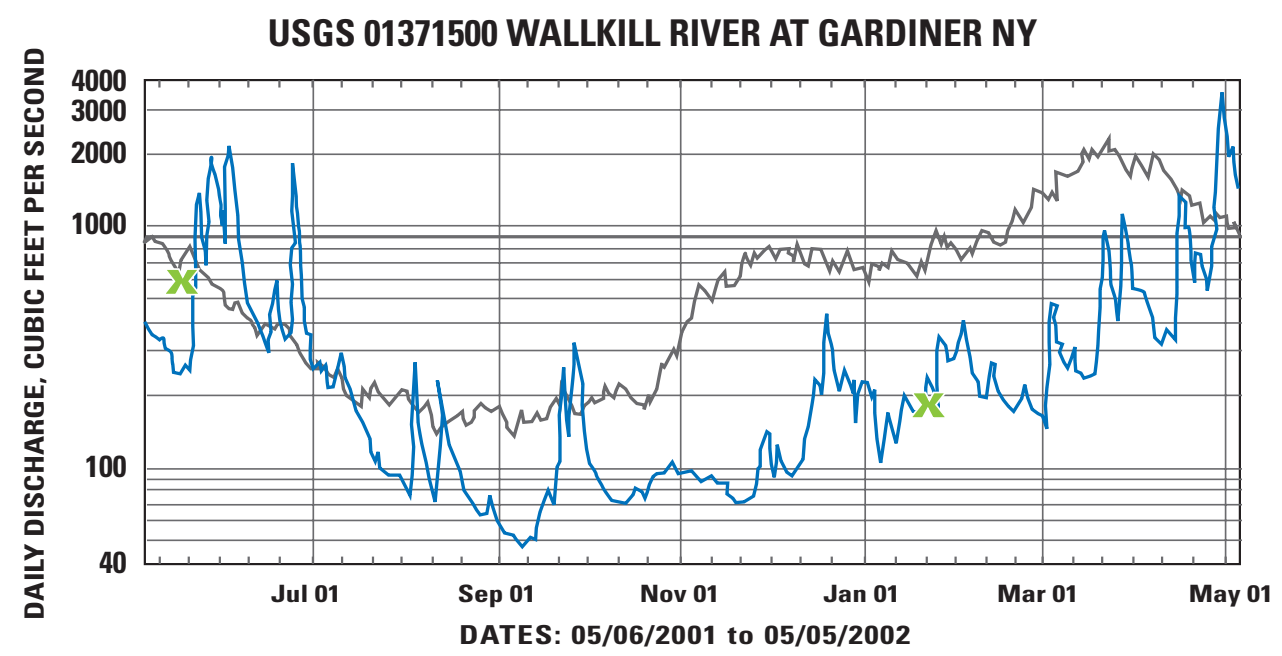

EXPLANATION

- DAILY MEAN DISCHARGE

- MEDIAN DAILY STREAMFLOW BASED ON 76 YEARS OF RECORD MEASURED DISCHARGE

Figure 1. Comparison of current flow with median flow (data over time).

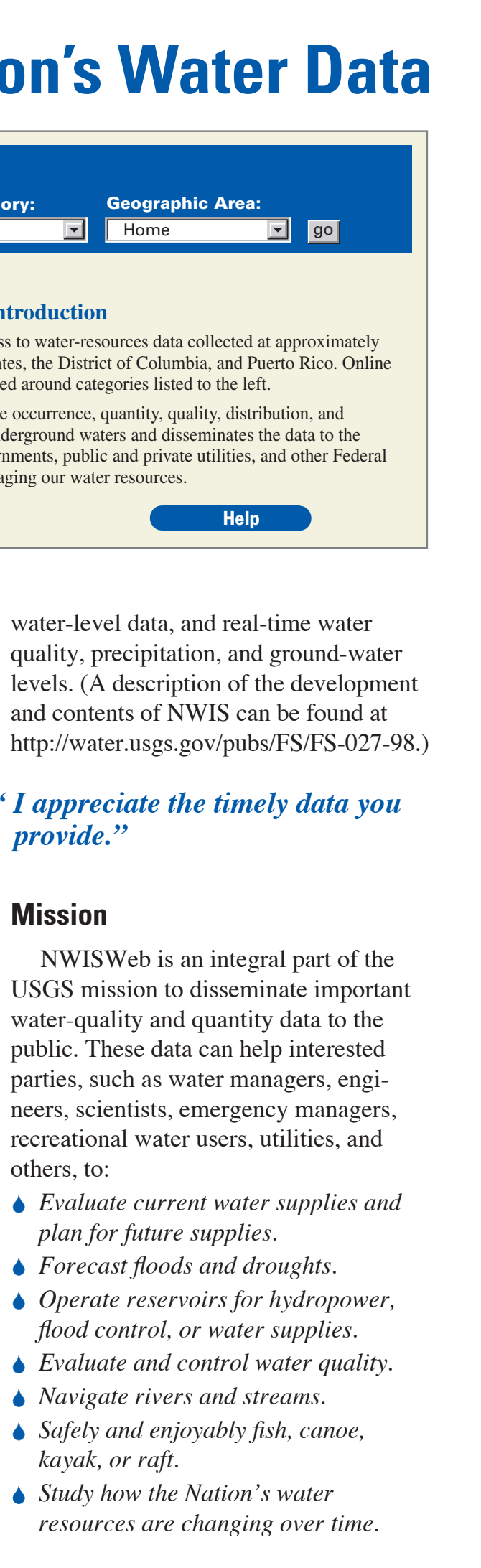

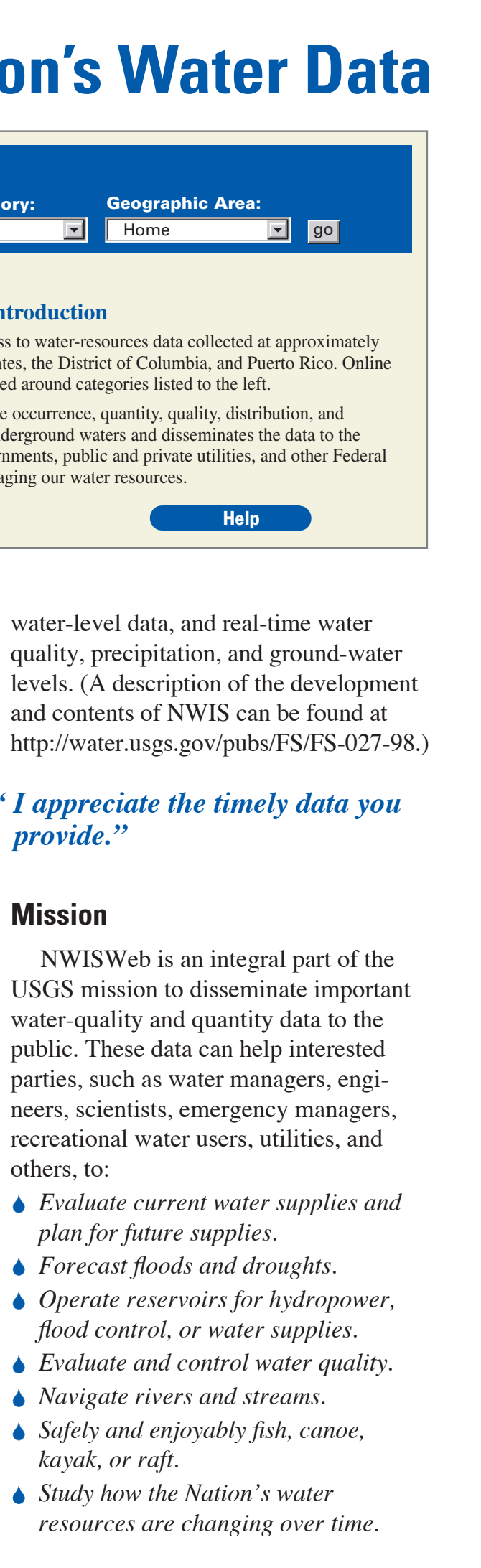

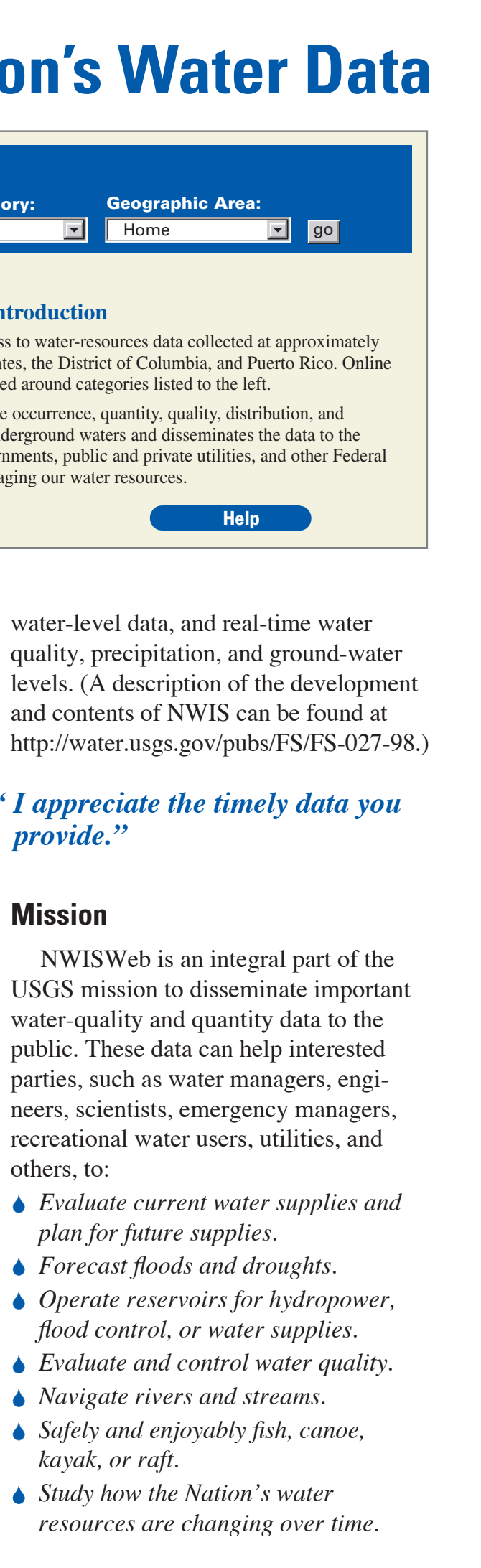

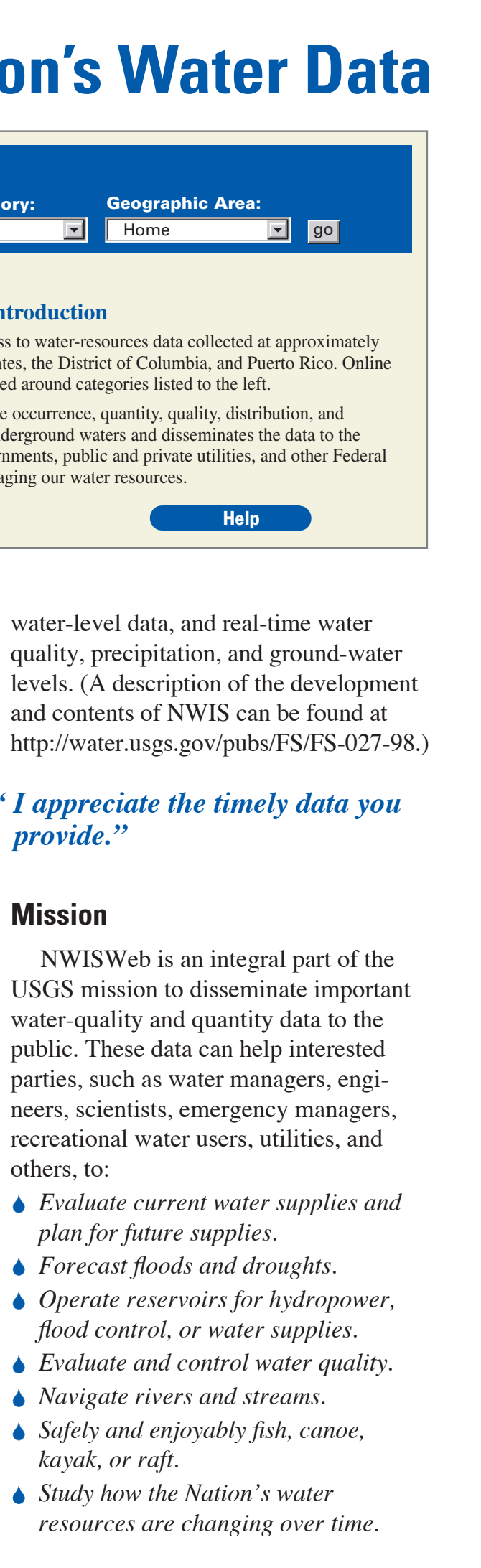

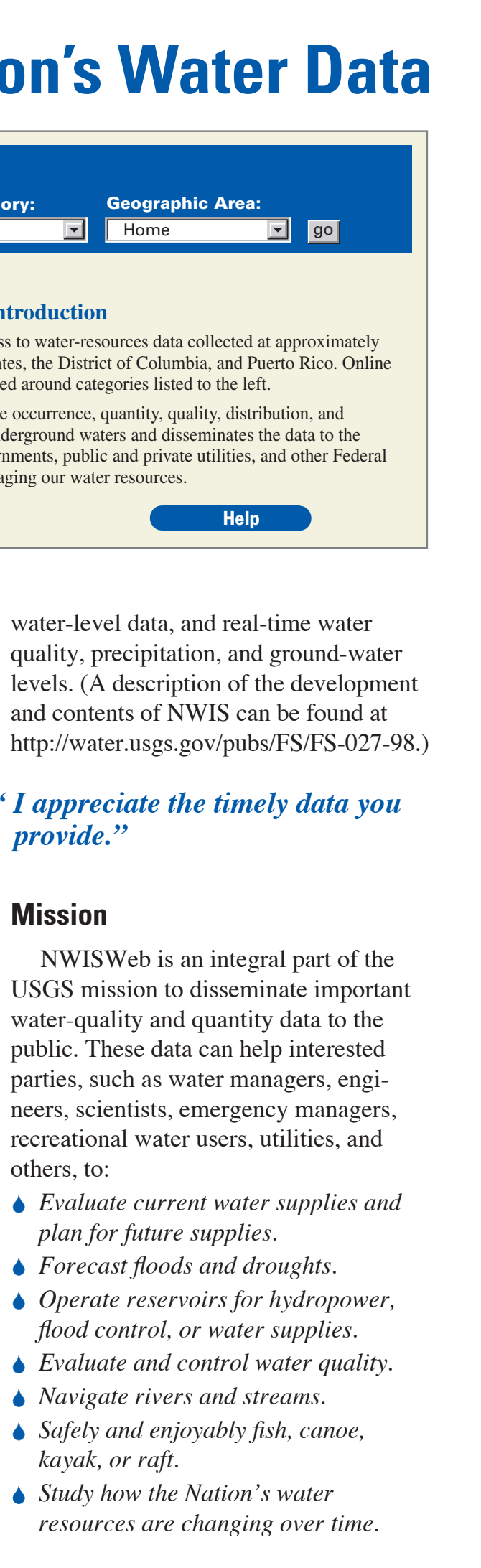

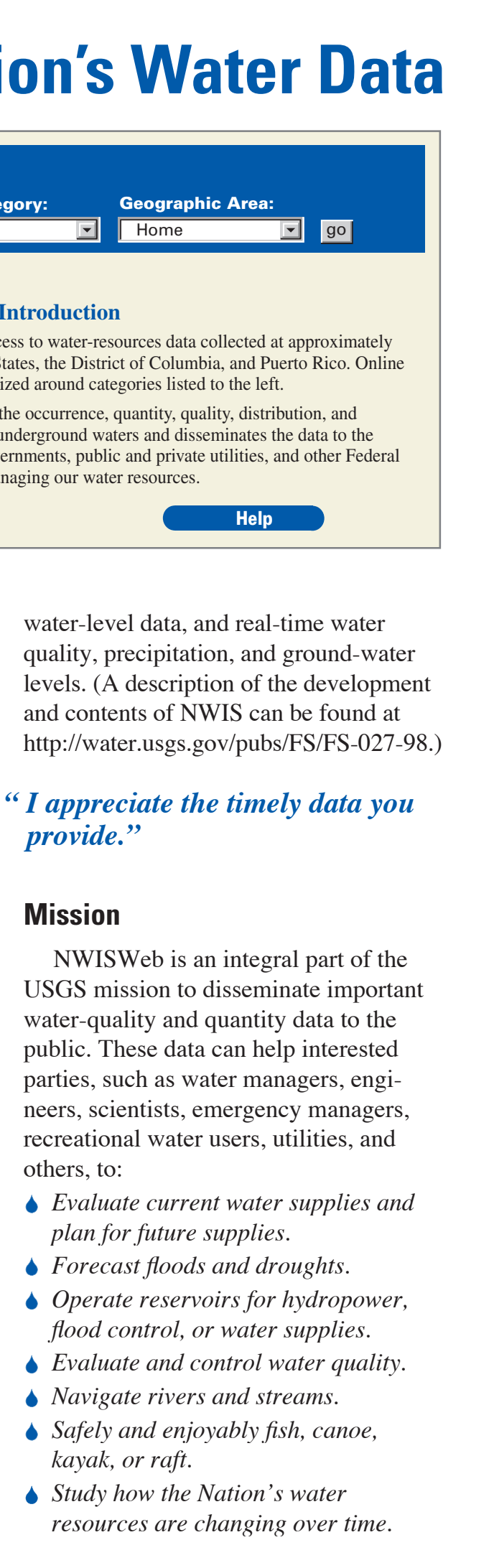

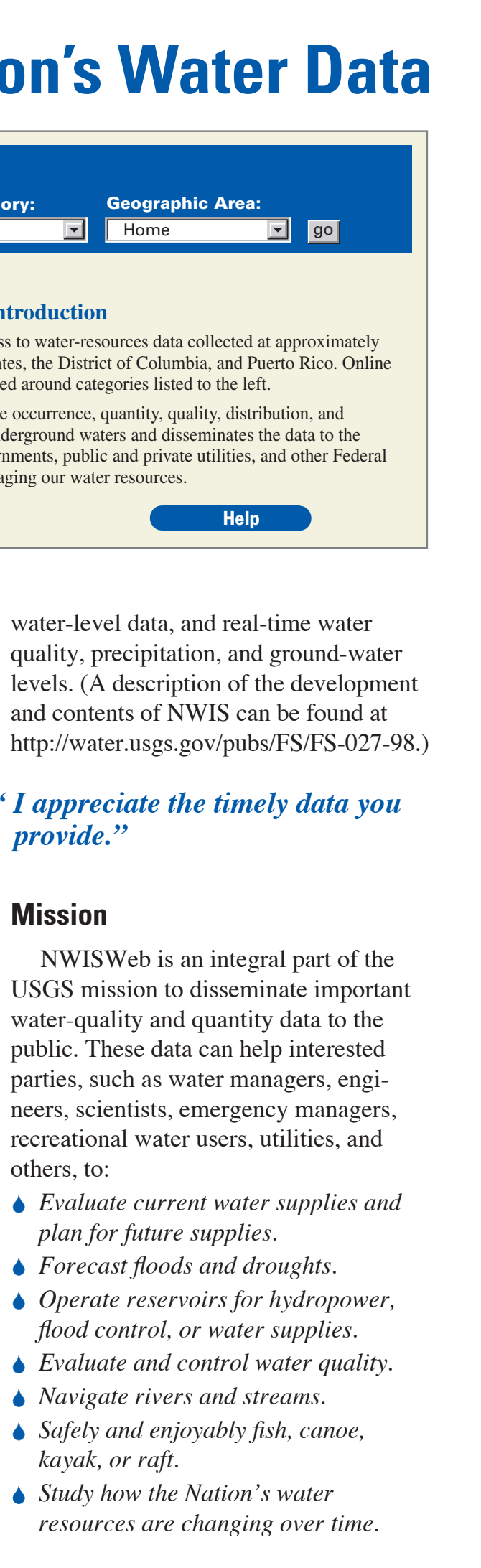

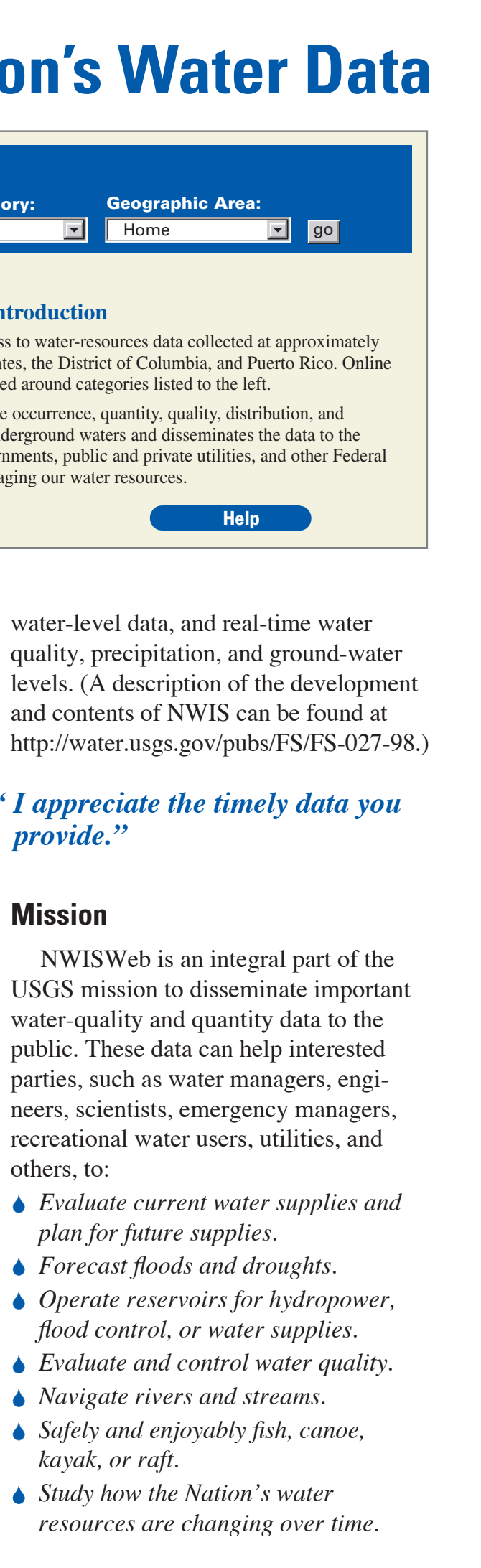

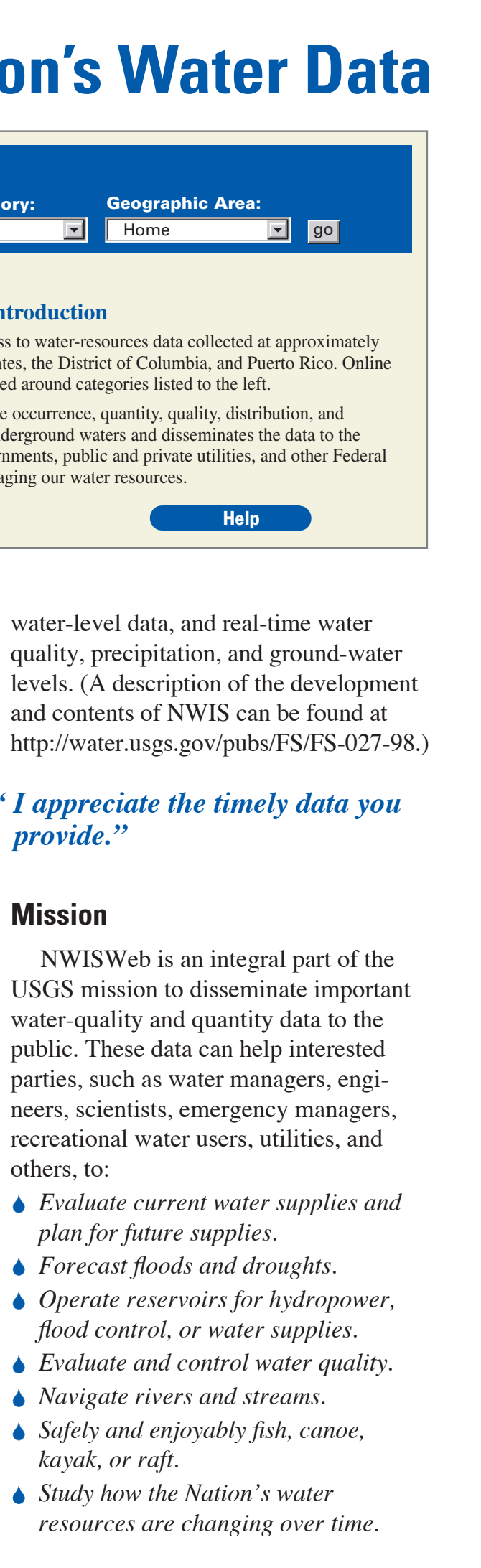

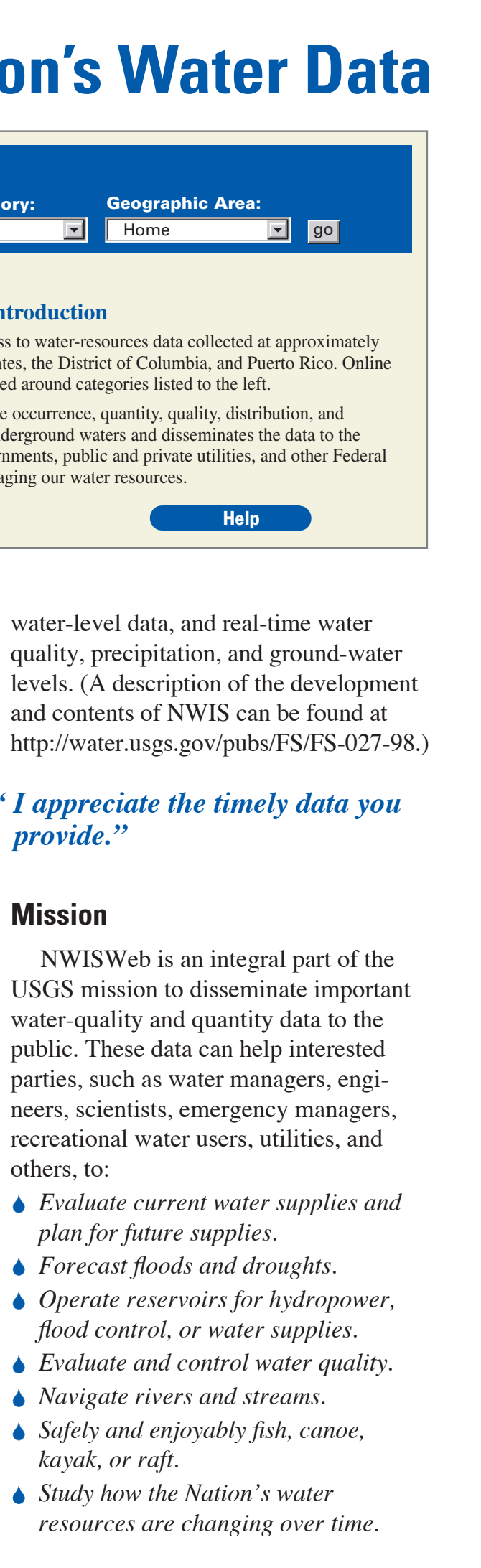

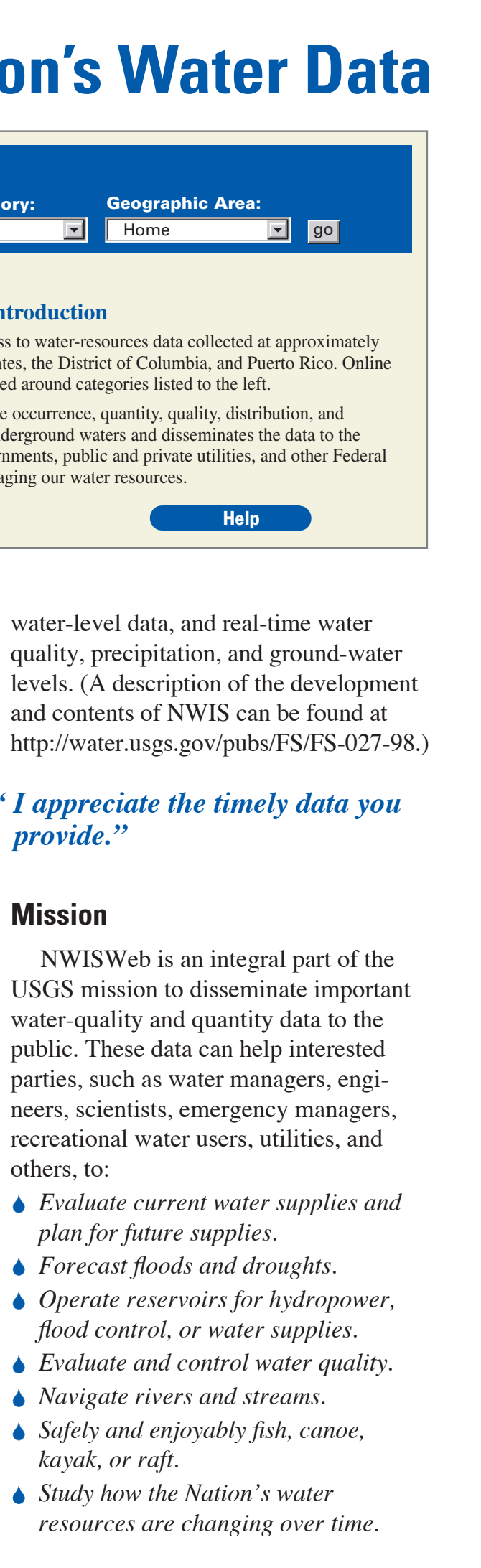

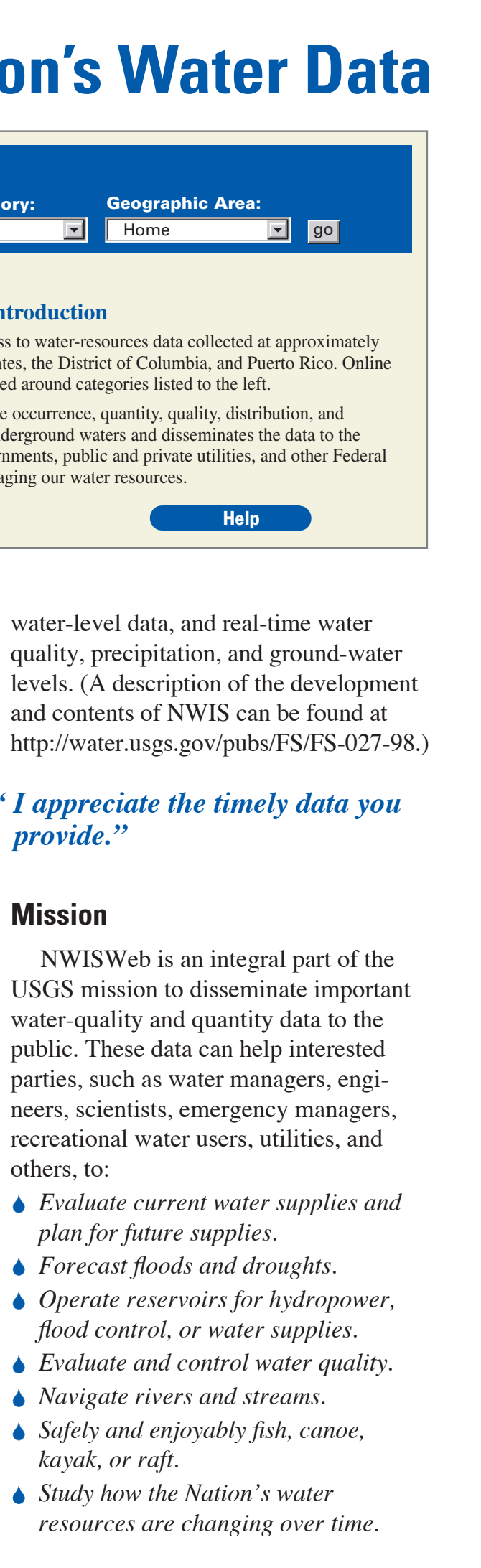

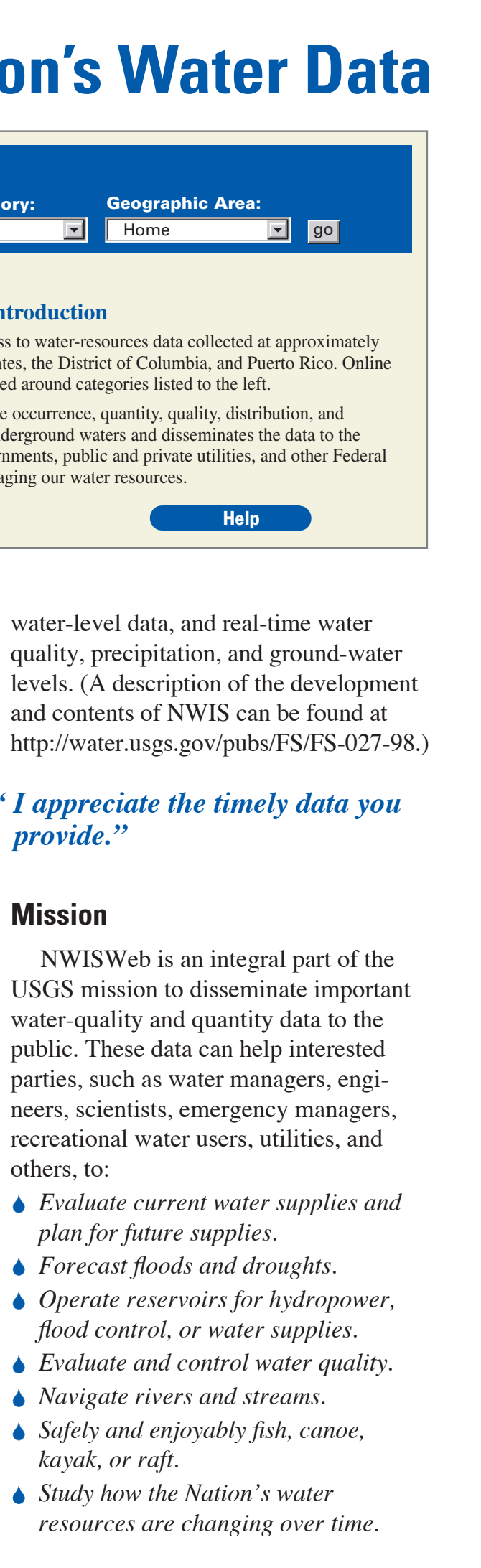

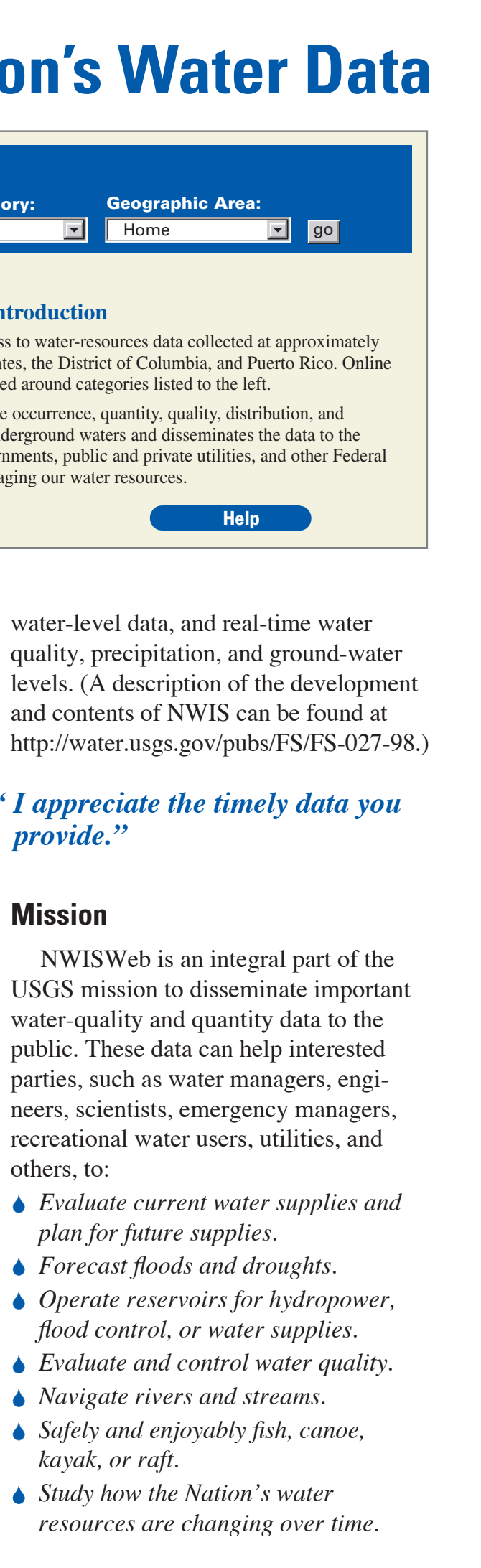

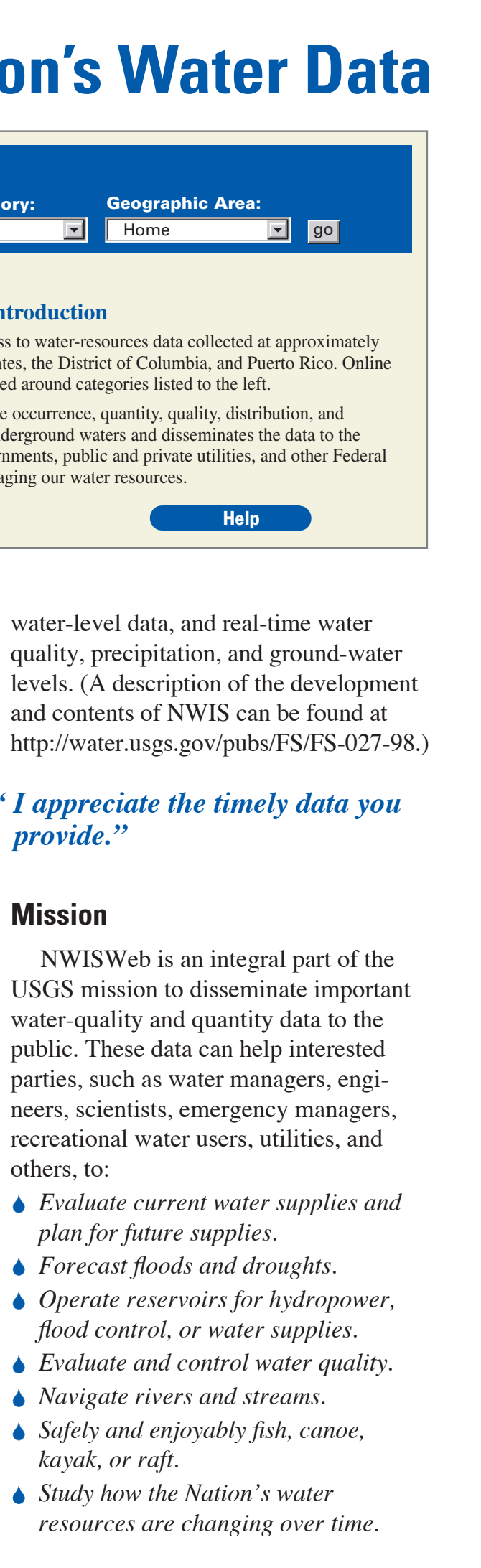

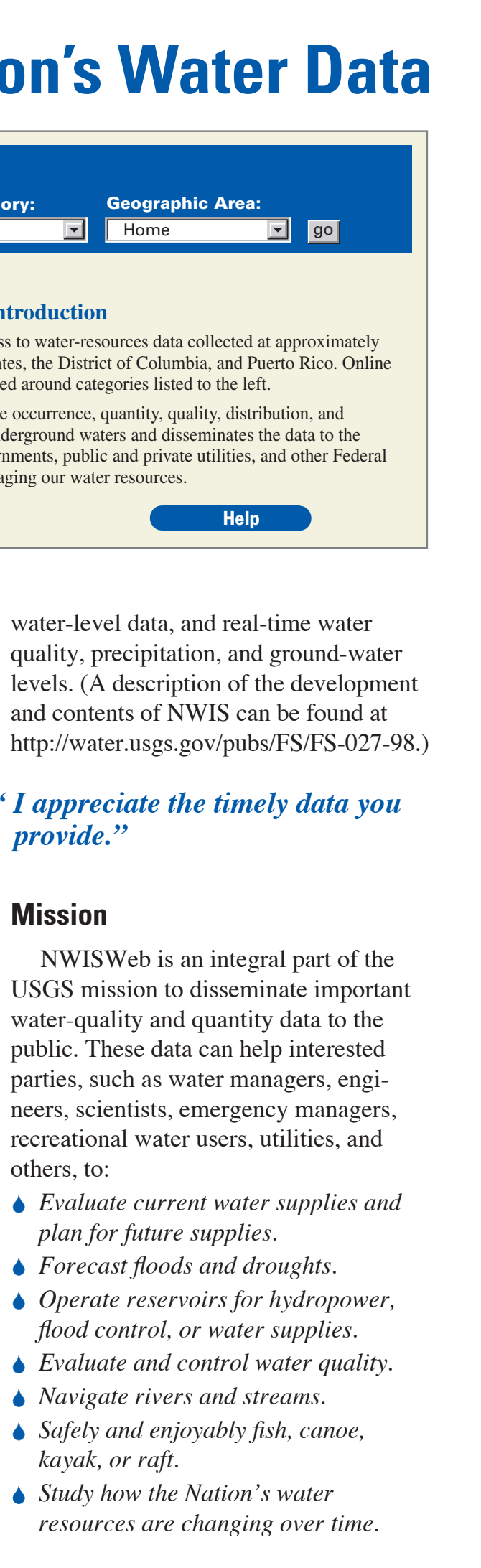

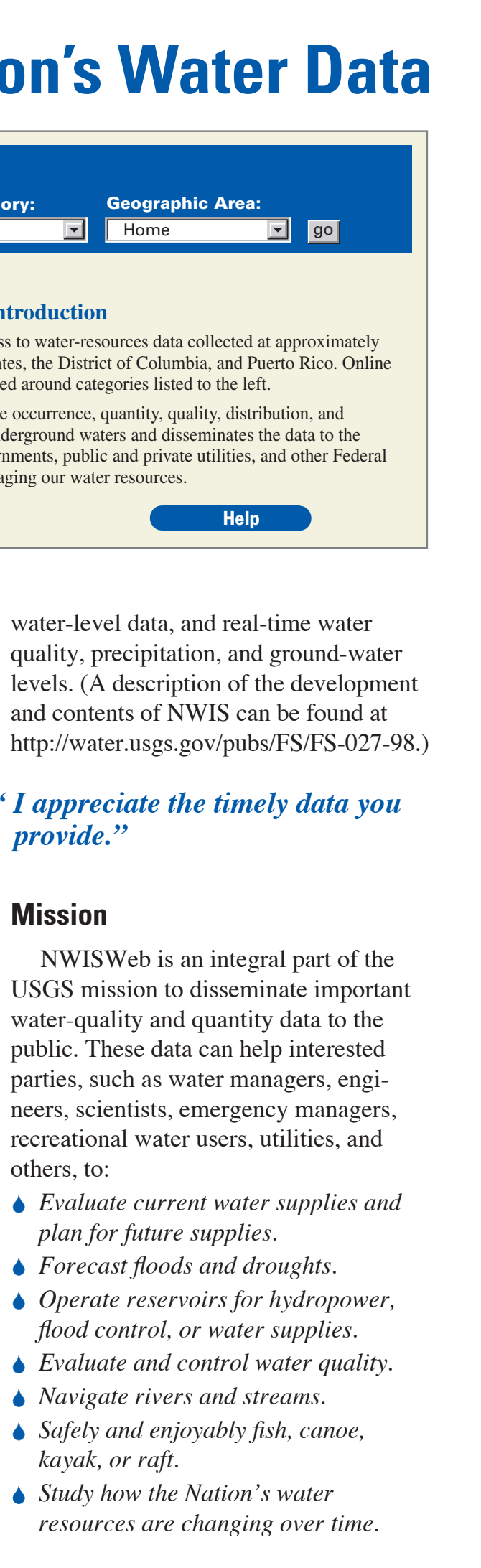

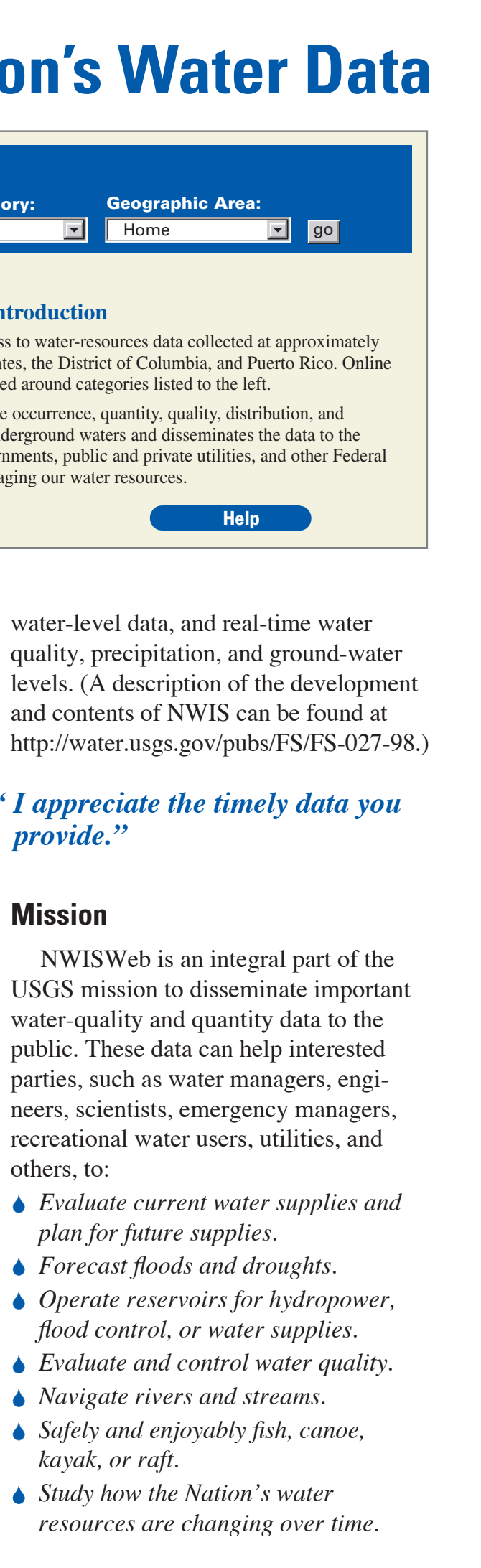

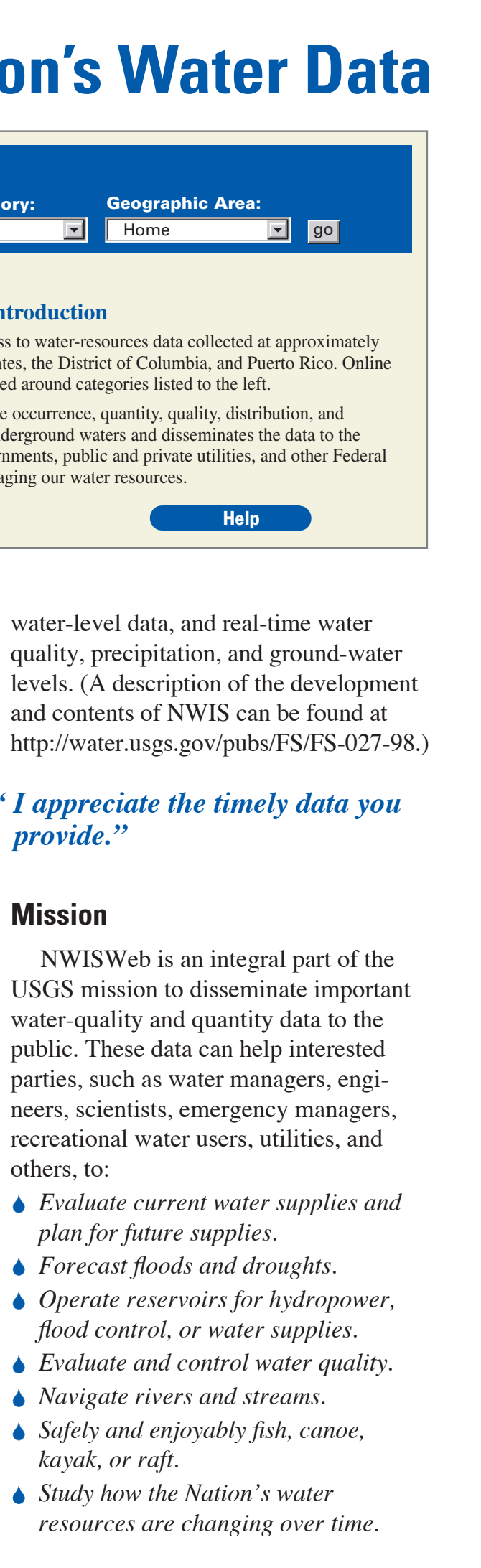

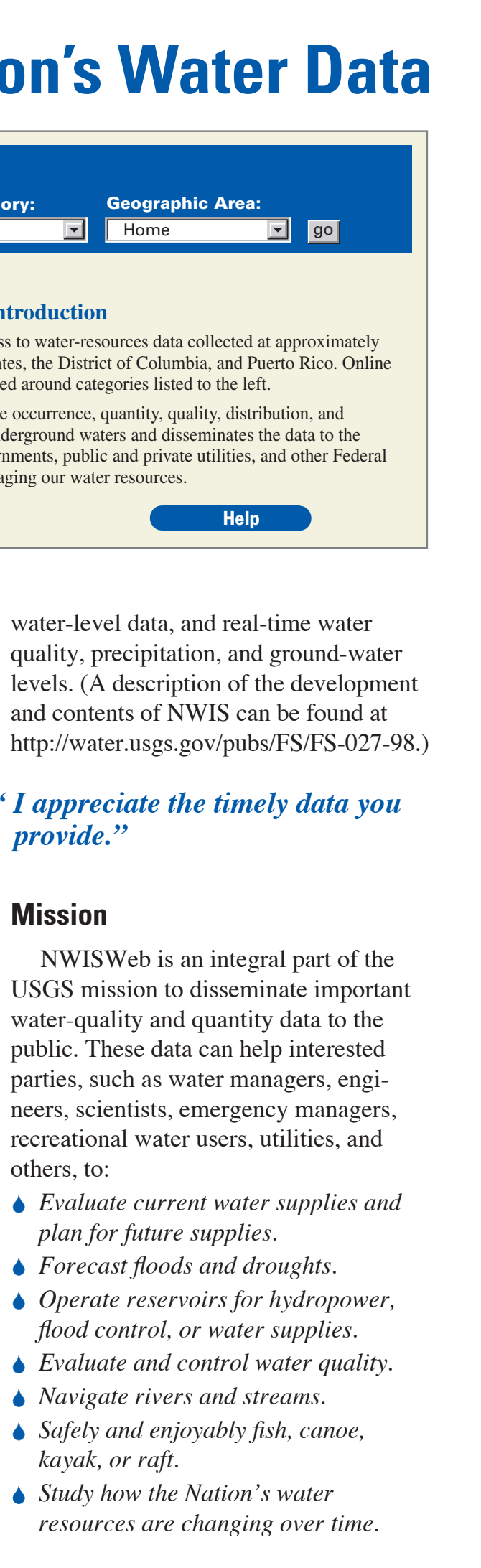

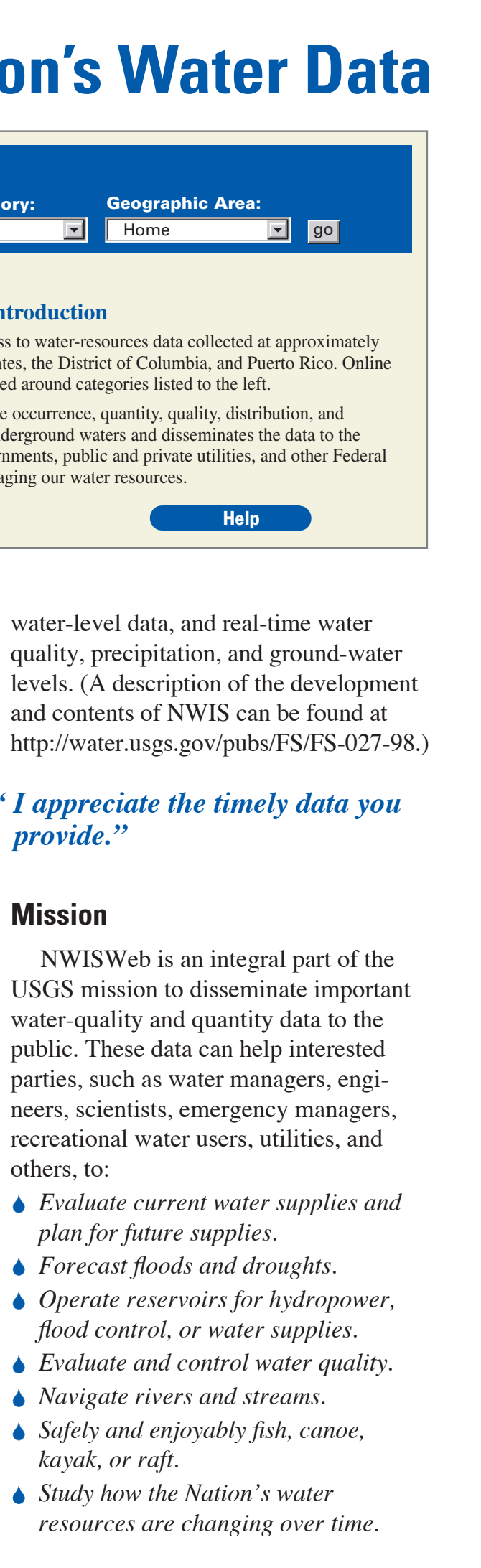

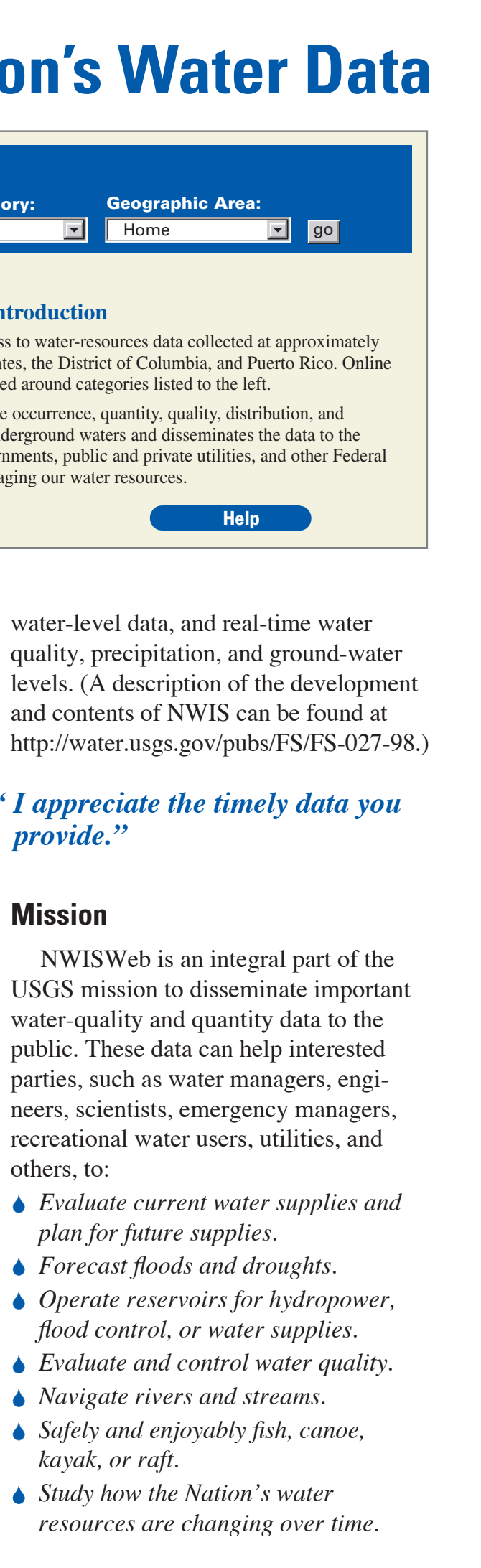

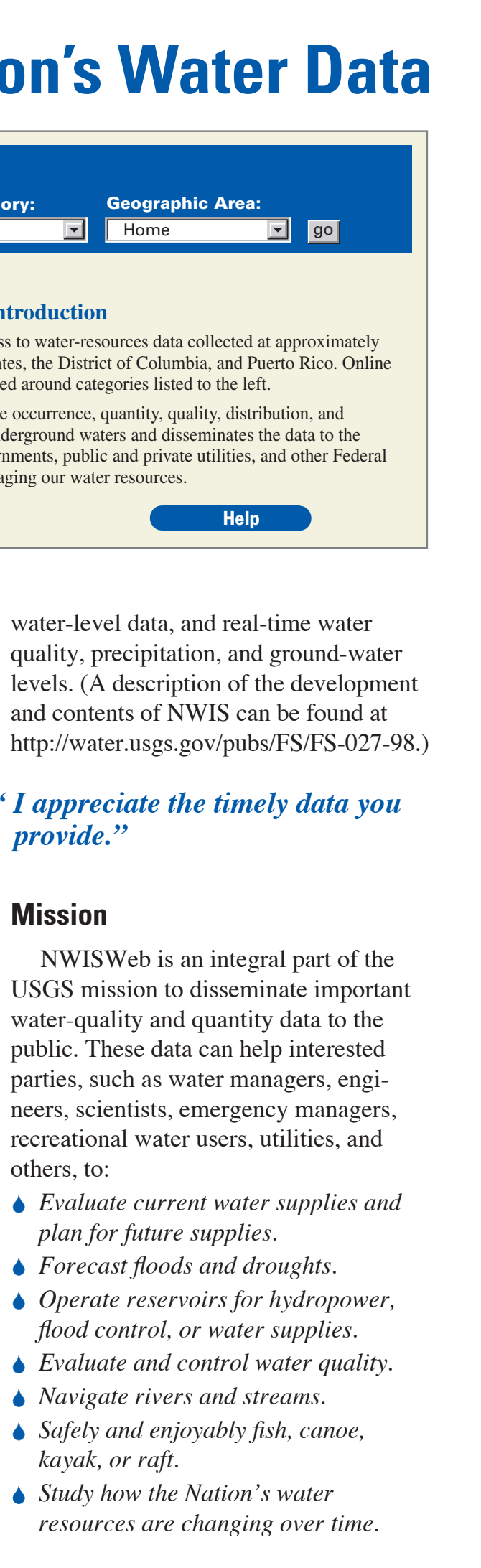

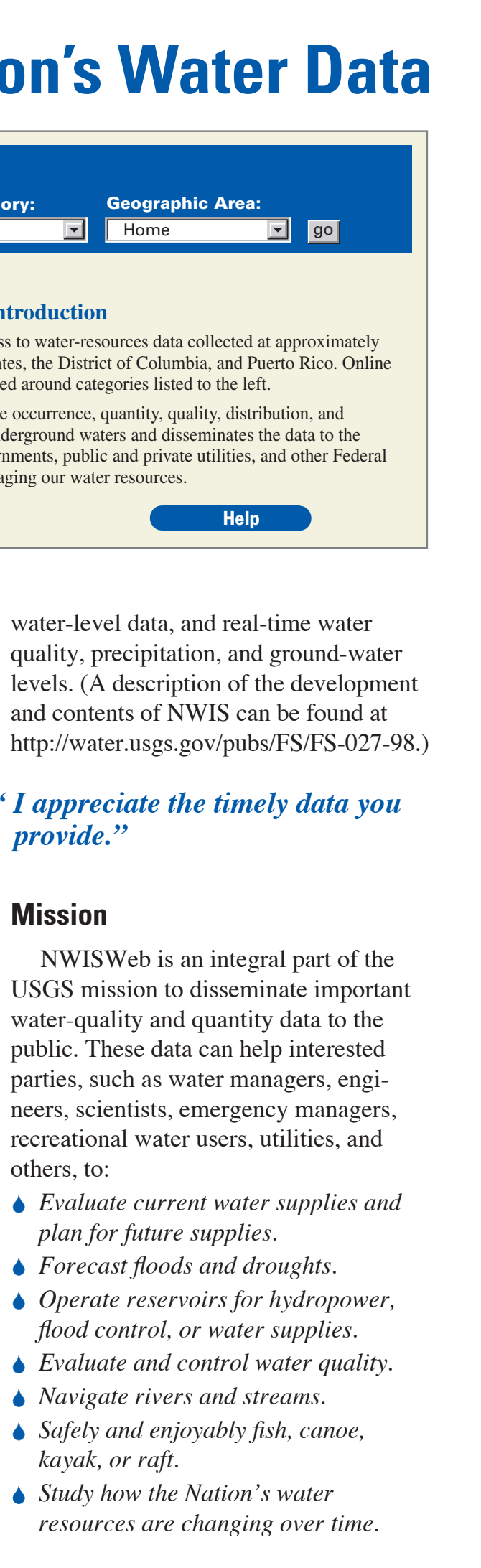

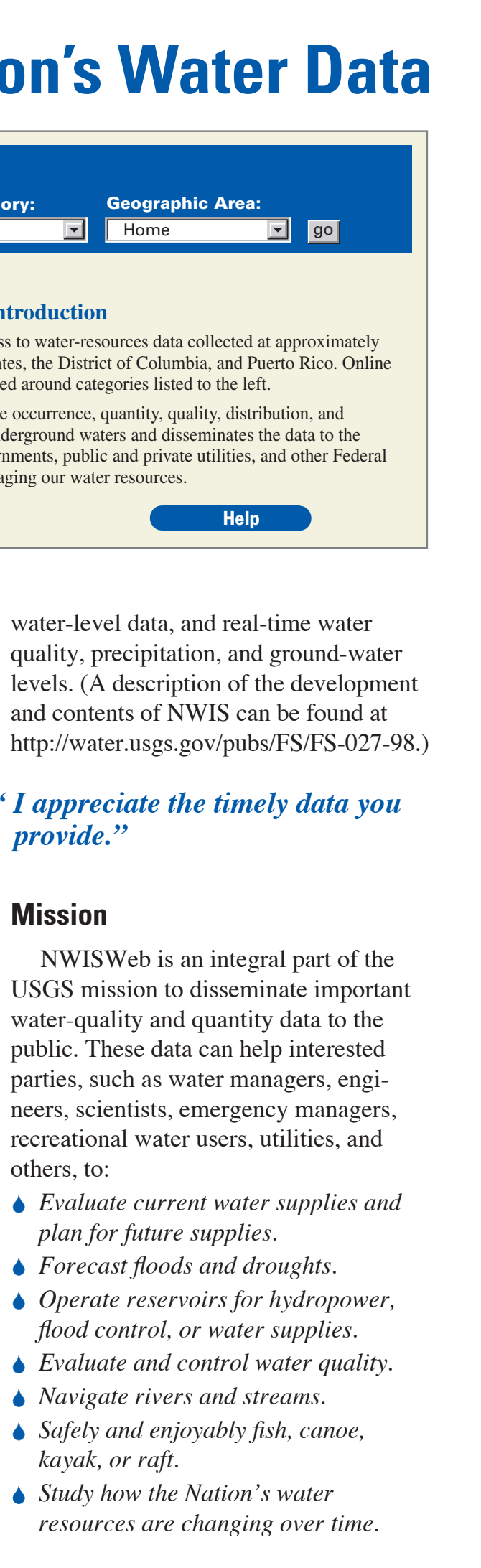

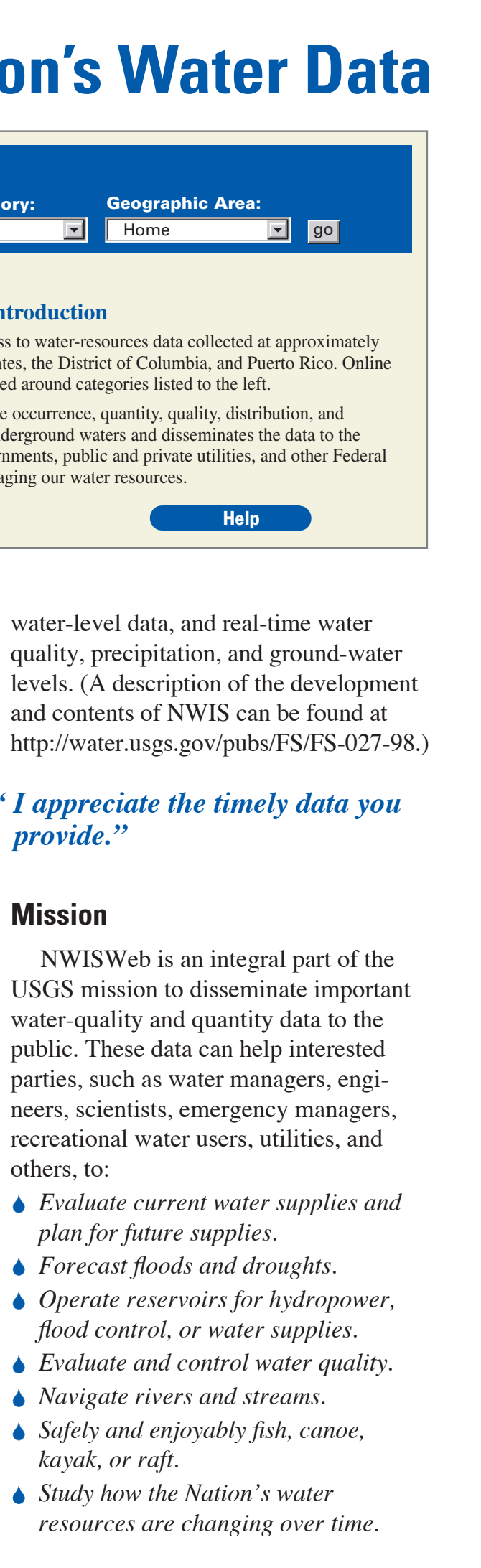

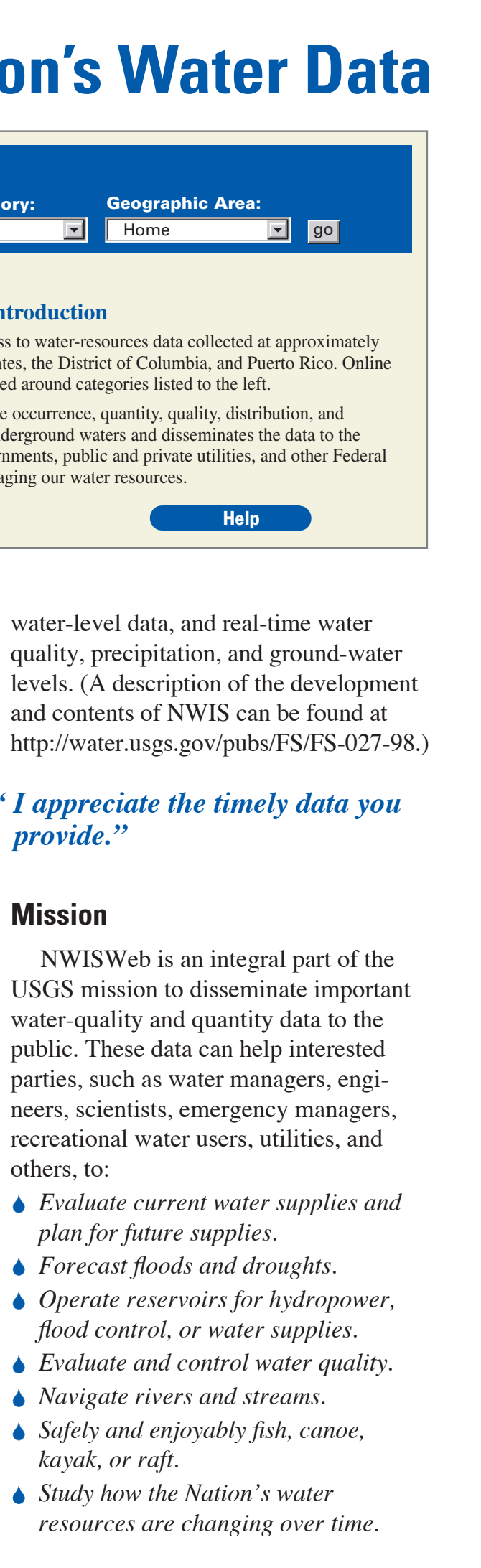




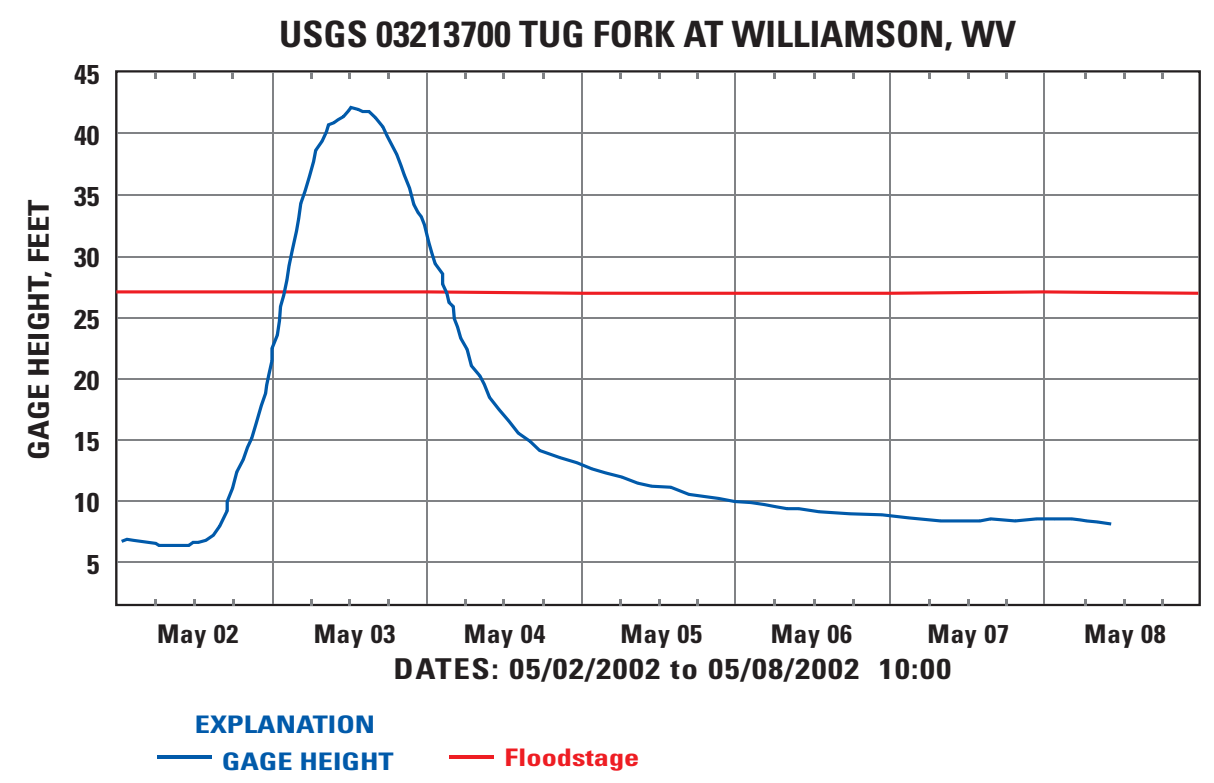

Figure 2. Monitoring river levels during a flood.

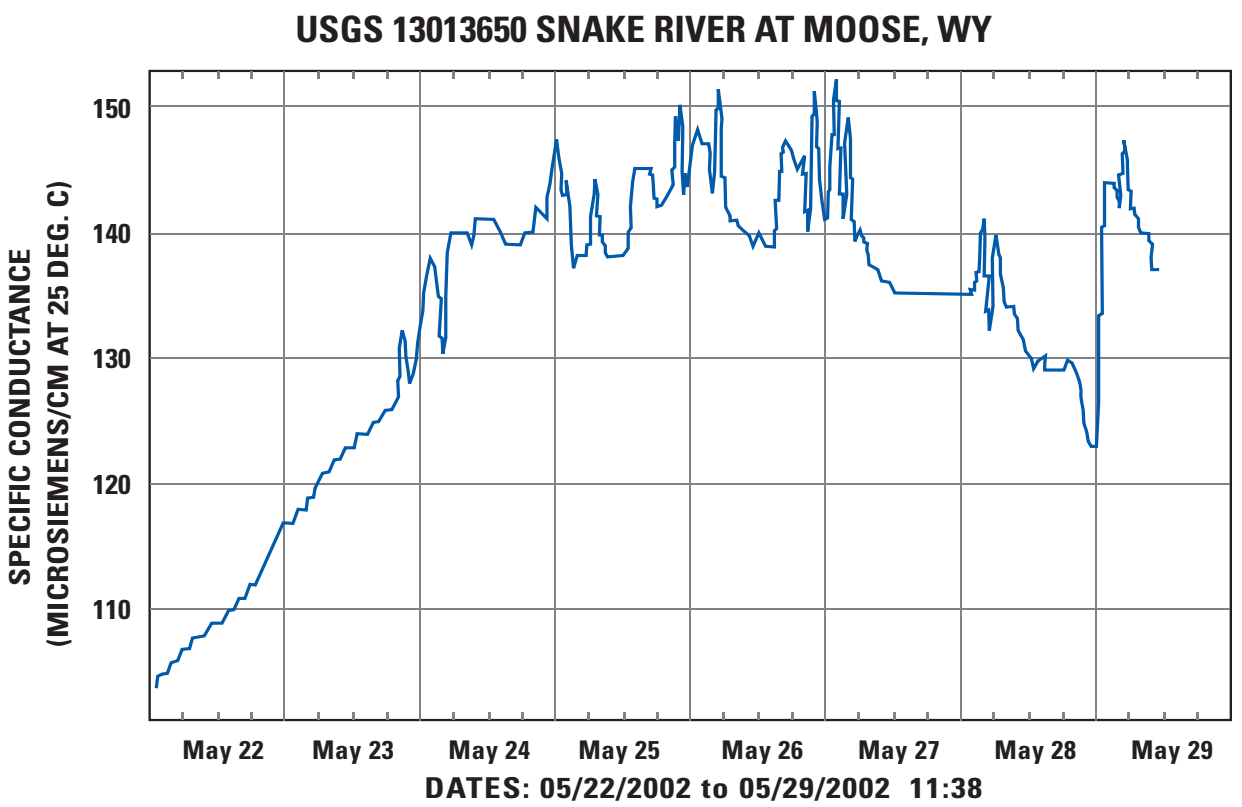

Figure 3. Monitoring chemical characteristics.

\section{Data Network}

NWISWeb data come from a nationwide network of more than 1.5 million USGS water-data collection sites, currently including:

- 315,000 water-quality sites where samples are taken from rivers or aquifers.

22,600 past and present streamflow sites.

8,830 real-time sites, including streams, lakes, reservoirs, groundwater, and meteorological sites.

- 1.40 million wells.
From this source network comes an array of water-data samples, as well as data values:

- 62.7 million chemical analyses that are based on 4.0 million water-quality samples.

- 181 million daily streamflow values.

- 635,000 flood-peak discharges.

- 7.1 million ground-water-level measurements.

"... imagine my amazement to find ground-water depth information and water-quality data online."

\section{Monitoring}

At selected surface-water and groundwater sites, the USGS maintains instruments that continuously record physical and chemical characteristics of the water for such information as water level, flow, $\mathrm{pH}$, specific conductance, temperature, dissolved oxygen, and percent dissolved-oxygen saturation. A list of the many parameters can be found at http://waterdata.usgs.gov/nwis/ current?submitted_form=introduction .

The data is normally transmitted by modem or satellite once every 4 hours and is processed automatically at USGS offices and made available within minutes. NWISWeb improves efficiency in USGS research and data retrieval operations. Most users can obtain the information they need directly from NWISWeb. The system also allows USGS scientists to better quality-assure data as it is received from the monitoring sites.

"Your website will REALLY be helpful the next time we have to monitor a flooding situation in our (radio stations's) coverage area."

\section{Functionality}

A single interface allows access to data from the entire Nation and enables users to easily compare data spatially over time to track changes. Navigation features allow users to start their search by specifying the data type of interest and to search the entire Nation or a specific State. Users select exactly how they want to see the data they request - as graphs, tables, or files they can download. They can also create their own Web site bookmarks to make requests for tailored outputs that they expect to use repeatedly. The bookmarking feature gives users the output they want when they reconnect to the Web site in a few hours, weeks, or months. Those users who expect to make large or frequent requests are urged to e-mail gs-W_support_NWISWeb @usgs.gov to work with USGS staff to identify the best way to get data they need.

\section{For more information, please contact:}

Chief, NWIS

U.S. Geological Survey

437 National Center, Reston, VA 20192

email: h2oteam@usgs.gov 